\title{
Knowledge of secondhand smoke and behaviour towards its exposure among teachers in Mauritius
}

\author{
Marie Chan Sun', Jean D. S. Frédéric²
}

\begin{abstract}
INTRODUCTION A literature review has revealed an absence of studies investigating the knowledge and behaviour of teachers towards secondhand smoke (SHS). This study was thus designed with the following objectives: 1) Assess the knowledge of SHS among primary school teachers, 2) Determine their behaviour towards SHS, and 3) Identify any relationship between knowledge and behaviour of participants.

METHODS A national cross-sectional study was conducted among a representative sample from 28 primary schools in all four educational zones of Mauritius in 2017. A self-administered questionnaire was used to collect data from primary school teachers. Data analysis was performed on 389 questionnaires.

RESULTS The mean knowledge score was found to be 28.9 ( $\mathrm{SD}=4.8$ ), which is just above the threshold score $(>27)$ for good knowledge. Less than two-thirds of the participants $(63.2 \%)$ were in the 'good knowledge' category. The mean behaviour score was found to be 26.6 ( $\mathrm{SD}=6.8$ ), which is situated in the range for 'satisfactory behaviour' in terms of avoiding SHS. Pearson correlation testing revealed a significant association between knowledge of SHS and behaviour towards exposure to SHS.

CONCLUSIONS This study showed that nearly two-thirds of teachers had good knowledge of the health dangers of SHS and applied this knowledge in their behaviour by keeping away from cigarette smoke.
\end{abstract}

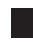

\section{AFFILIATION}

1 Department of Medicine, Faculty of Science, University of Mauritius, Réduit, Mauritius

2 Faculté de Médecine, Université de Bordeaux, Bordeaux, France

\section{CORRESPONDENCE TO}

Marie Chan Sun. Department of Medicine, Faculty of Science, University of Mauritius, Réduit, 80837, Mauritius. E-mail: lan.sun@ uom.ac.mu

\section{KEYWORDS}

knowledge, behaviour, teachers, secondhand smoke, Mauritius

Received: 7 January 2020

Revised: 17 April 2020

Accepted: 21 April 2020

\section{INTRODUCTION}

Cigarette smoke, considered as simply unpleasant fifty years ago, has now been acknowledged as being deadly noxious based on scientific evidence of the association of secondhand smoke (SHS) with various diseases. According to the World Health Organization (WHO) (2019), SHS causes more than 1.2 million premature deaths per year ${ }^{1}$. The need for protection from exposure to SHS has thus been addressed in Article 8 of the World Health Organization Framework Convention on Tobacco Control (WHO, 2003), which stipulates comprehensive smoking-free policies in public places ${ }^{2}$. There is well-established evidence that exposure to SHS is associated with public health harms, which include premature death, lung cancer, chronic obstructive pulmonary disease and coronary heart disease ${ }^{3-6}$. Being a significant cause of heart and lung diseases, SHS increases the risk of lung cancer of exposed non-smokers by $20-30 \%$, the risk of coronary heart disease by $25-30 \%$ and the risk of stroke by $20-30 \%{ }^{7-9}$.

Children are even more vulnerable to the toxicity of SHS as their body is still developing ${ }^{7,10,11}$. There is also well-established evidence that exposure to SHS by pregnant women is associated with low birthweight ${ }^{6,12}$, risk of cot death ${ }^{6,13}$, middle ear infection ${ }^{6,14,15}$ and exposure of children to lower tract respiratory infections ${ }^{6,14,16,17}$. A recent study among women in Ethiopia showed that respondents' knowledge on the specific health risks 
associated with tobacco use and SHS exposure was limited ${ }^{16}$. Another study among school children and community adults in four cities in China, India, Mexico and England showed that the specific health effects of tobacco use and SHS exposure were poorly understood ${ }^{17}$. In a cross-sectional study among adults living in private households in the UK, the knowledge of SHS-related illnesses, especially the non-respiratory conditions, was found to be low ${ }^{18}$. On the other hand, studies among highly educated groups like university students ${ }^{19,20}$ or university employees ${ }^{21,22}$ demonstrated good or at least adequate SHS knowledge levels. Some studies showed that children had the knowledge that SHS is harmful ${ }^{23,24}$ while others revealed that a good proportion did not even know its meaning ${ }^{23}$.

Considering the vulnerability of children, we perceive that teachers need to be empowered so that they pass on the health-related information to their students. The literature review has revealed the absence of studies investigating the knowledge and behaviour of teachers toward SHS. We attempt to fill this gap with the present study among school teachers in Mauritius. It is highlighted that Mauritius became a leader in tobacco control in Africa since the country signed in June 2003 and ratified in May 2004 the World Health Organization Framework Convention on Tobacco Control (FCTC). In order to fulfil its obligations under the FCTC, Mauritius passed the Public Health (Restrictions on Tobacco Products) Regulations 2008, which include smoking bans in public places to protect people from the dangers of cigarette smoke, bans on tobacco advertising/promotion/sponsorship, and bans on the sale of cigarettes to and by minors.

People's knowledge of the impact of SHS on health and the role of this knowledge on behaviour have not been thoroughly investigated ${ }^{18}$. The current controversial literature on the relationship between knowledge and behaviour lends support for additional studies to contribute to the literature with a view to building consensus. The present study has thus been designed with the aim to investigate the relationship between the knowledge of SHS and the behaviour towards SHS among primary school teachers in Mauritius. The objectives of the study are: 1) Assess the knowledge of SHS among primary school teachers, 2) Determine their behaviour towards exposure to SHS, and 3) Evaluate the relationship between knowledge and behaviour.

\section{METHODS}

\section{Study design}

This is a national cross-sectional study among teachers working in either public or private aided primary schools in Mauritius during 2017. On the basis of the size of the four educational zones of Mauritius, random cluster sampling technique was used to determine the number of schools which were $9,8,7$ and 4 in the respective educational zones. The number of school teachers to be targeted was calculated by using the formula $S=Z^{2} p(1-p) / M^{2}$, where $S$ is the sample size, $\mathrm{p}$ the population proportion, $\mathrm{M}$ the margin of error being 0.05 and the $\mathrm{Z}$ score being 1.96 with confidence level of $95 \%$. The sample size was estimated to be 385 . The study population consisted of teachers enrolled through the Mauritius Institute of Education and working in any of the 28 randomly identified primary schools in Mauritius. This study received ethical clearance from the Ethics Committee of the Ministry of Health and Quality of Life of Mauritius. Prior authorization to have access to the public and private schools of the four zones of Mauritius was obtained from the Ministry of Education and Human Resources, Tertiary Education and Scientific Research, and the Service Diocésain de l'Education Catholique. Anonymity and confidentiality of data have been maintained throughout the research process.

\section{Data collection}

Permission from the respective principals of the randomly identified schools was sought prior to distribution of the survey documents, which included a cover letter, a participation information sheet, a written consent form and the self-administered survey questionnaire. Data were collected by means of a survey instrument adapted from the one initially designed by Chan Sun ${ }^{25}$ and pre-tested by Nuzooa ${ }^{19}$. A pilot study among a small group of 4 teachers showed that the adapted questionnaire suited the objectives for the study population of school teachers. Their responses were added to the total number of questionnaires completed.

\section{Measures}

The instrument used for this study included: 1) a 
9-item list of statements to assess knowledge of SHS with responses on a 5 -point Likert scale, 2) a 9-item list of statements to investigate behaviour towards exposure to SHS with responses on a 5-point Likert scale, and 3) a section to collect sociodemographic details. The sociodemographic section consisted of the characteristics: gender, age, smoking status, and duration of teaching experience.

The responses to the knowledge/behaviour items in the questionnaire were given the scores: Strongly Agree: 4, Agree: 3, Don't know: 2, Disagree: 1, and Strongly Disagree: 0 . It is to be noted that the grading has been adapted for this study so that the neutral point (Don't know) is at the centre of the 5-point Likert scale (Don't know $=2$ ) and not at the end as in the original questionnaire grading (Don't know $=0$ ). This has been done for a more comprehensive and reliable reflection of the knowledge/behaviour of participants. In the behaviour component, questions 6,8 and 9 were reverse questions.

A knowledge/behaviour score was computed for each subject from the responses reported by adding up the score for each component into a total score. The addition of the scores for the respective responses to the knowledge/behaviour items led to the knowledge/behaviour score, which had a range from 0 to 36 . For both measures, the higher the score the better the knowledge/behaviour.

Cut-off points were based on the grading system used by El Sherbiny et al. ${ }^{26}$ to categorize knowledge as follows: Poor Knowledge corresponds to $<50 \%$ of total score, Satisfactory Knowledge is $50-75 \%$ of total score and Good Knowledge is $>75 \%$ of total score. Based on these criteria, the knowledge/behaviour scores calculated in this survey were categorized as Good Knowledge (score $>27$ ), Satisfactory Knowledge (score 18-27) or Poor Knowledge ( score $<18$ ).

\section{Data analysis}

For data entry and statistical analysis, the Statistical Package for Social Sciences for Windows version 23 was used. An alpha level of less than 0.05 was considered as statistically significant for all inferential analyses. Correlation and linear regression analyses were performed to determine association between investigated variables. Pearson's correlation was performed to evaluate the relationship between knowledge and behaviour. Parametric test was used on the basis that both measures are obtained from Likert scales and considered as continuous data, in line with Norman ${ }^{27}$ who put forward the reliability of parametric analyses on Likert Scale data.

\section{RESULTS}

A total of 401 questionnaires were completed but 12 were excluded from the study due to missing values (partial completion). The total number of questionnaires analysed for the purpose of this study was 389 .

\section{General characteristics of sample}

The sample consisted mainly of females (79.9\%) and $20.1 \%$ were males. The age of the participants ranged from 24 to 63 years old. The mean age was 39 years $(\mathrm{SD}=9.3)$. The prevalence of current smokers in the study population was $6.2 \%$. The duration of teaching experience ranged from 0 to 44 years of practice, with the mean working experience being 15.9 years $(\mathrm{SD}=9.5)$.

\section{Knowledge of SHS}

\section{Knowledge and frequencies}

As illustrated in Table 1, nearly all the subjects were knowledgeable that SHS contains toxic substances (98\%) and that it is harmful (99\%) to the health of people nearby. The percentage agreement for 'There is no safe level of exposure to secondhand smoke' and 'There have been a number of cases where nonsmokers developed lung cancer because of exposure to secondhand smoke' was high too, amounting to $92.5 \%$ and $89.5 \%$, respectively. Participants were, however, less knowledgeable of the effects of SHS on other organ systems and on children. The statements in relation to 'SHS exposure as a cause of SIDS' and 'SHS exposure as increased risk of ear infections' yielded neutral responses ('Don't know') among $40.6 \%$ and $51.4 \%$ of participants, respectively.

\section{Knowledge score}

The mean knowledge score was found to be 28.9 ( $\mathrm{SD}=4.8)$, which is just above the threshold score $(>27)$ for good knowledge. Less than two-thirds of the participants $(63.2 \%)$ were in the 'Good Knowledge' category (63.2\%) while more than one- 
Table 1. Percentage (\%) responses to components of the knowledge scale, Mauritius, 2017 (N=389)

Statements

1. Breathing smoke from other people's cigarette is harmful to one's health.

2. Secondhand smoke contains substances known to be toxic.

3. There is no safe level of exposure to secondhand smoke.

4. There have been a number of cases in which nonsmokers developed lung cancer because of exposure to secondhand smoke.

5. Exposure to secondhand smoke has immediate adverse effect on cardiovascular system.

6. Risk of having coronary heart diseases increases when exposed to secondhand smoke.

7. Maternal exposure to secondhand smoke during pregnancy causes low birthweight.

8. Exposure to secondhand smoke is associated with Sudden Infant Death Syndrome (SIDS).

9. Children who are exposed to secondhand smoke are at increased risk of having ear infections.

\section{Strongly \\ disagree}

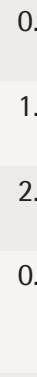

1.0

6.2

12.1

45.0

45.8

10.3

15.2

36.0

40.6

29.8

18.8

2.6

8.5

51.4

24.7

12.9

third $(35.5 \%)$ were in the 'Satisfactory Knowledge', knowledge and working experience. This nonwith a very small percentage in the 'Poor Knowledge' $(1.3 \%)$ category.

\section{Knowledge and teaching experience}

Spearman's correlation test was used to assess the null hypothesis that there is no relation between parametric method was used as an alternative to Pearson's correlation test as assumption for normality was not met, $\mathrm{p}<0.05$ (Kolmogorov-Smirnov test). A mild positive significant correlation was found between knowledge and working experience, $\rho(388)$ $=0.19, \mathrm{p}<0.001$ (Figure 1).

Figure 1. Correlation between knowledge and working experience, Mauritius, 2017 ( $\mathrm{N}=389)$ Knowledge and Working Experience

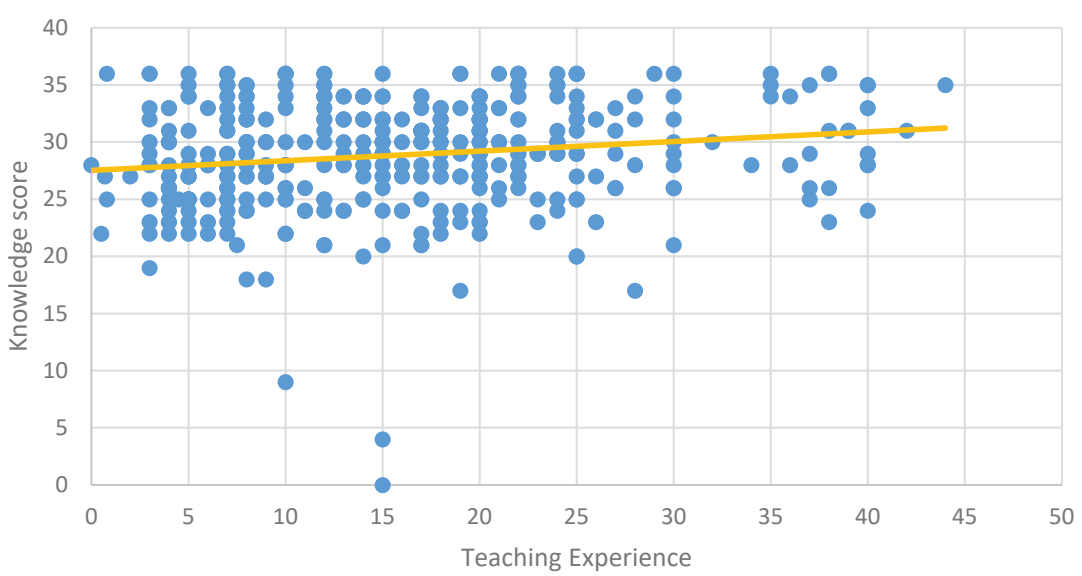


Table 2. Percentage (\%) responses to components of the behaviour scale, Mauritius, $2017(\mathrm{~N}=389)$

Statements

1. In case I am being exposed to the cigarette smoke of a stranger, I would surely ask the stranger to put out the cigarette.

2. I normally reduce the duration of conversation with a person who is smoking.

3. I avoid being part of a group of persons who are smoking.

4. I avoid talking to someone who is smoking.

5. I try to spend as little time as possible in places where smoking is prevalent.

6. I do not have any problem in having a chat with my family members while they are smoking.

7. If I am traveling by taxi and the driver starts to smoke, I would ask him to stop smoking.

8. Visitors are allowed to smoke in my house.

9. I would not have any objection if someone who is traveling in the same car as me starts to smoke.

\section{Strongly \\ disagree}

3.6

Disagree

Don't know

Agree

Strongly agree

15.4

2.3

39.3

39.3

3.1

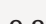

0.5

38.3

48.8

4.6

16.2

2.1

34.4

42.7

5.7

26.7

0.8

35.7

31.1

2.6

6.9

1.3

40.6

48.6

27.5

36.0

1.8

29.3

5.4

1.8

12.6

4.1

34.7

46.8

41.6

34.7

1.5

14.4

7.7

47.8

37.5

1.0

9.3

4.4

\section{Behaviour and frequencies}

Table 2 shows the behaviour of teachers towards SHS exposure. The statements with the highest agreement responses (by either agreeing or strongly agreeing to the statements) were: 'I try to spend as little time as possible in places where smoking is prevalent' (89.2\%) and 'I normally reduce the duration of conversation with a person who is smoking' (87.1\%). The participants were, however, less likely to 'avoid a group currently smoking' (77.1\%) and to 'avoid talking to someone who is smoking' (66.8\%). Teachers demonstrated some assertiveness as $78.6 \%$ of them would ask a stranger and $81.5 \%$ would ask the driver of a taxi to put out his/her cigarette. Statements 6, 8 and 9 were reversed statements aiming at reducing response bias. They reveal that $34.7 \%$ of the sample subjects would not do anything to reduce exposure while chatting with a family member who is smoking. Also, $76.3 \%$ of the participants have a home smoking ban and $85.3 \%$ are annoyed if anyone starts smoking while travelling in the same car.

\section{Behaviour score}

The mean behaviour score was found to be 26.6
$(\mathrm{SD}=6.8)$, which is just below the threshold score $(>27)$ for 'appropriate behaviour'. The mean behaviour score is thus situated at the upper limit for 'satisfactory behaviour' in terms of avoiding SHS.

\section{Knowledge and behaviour relationship}

Pearson's correlation testing revealed a mild positive relation: $r(388)=0.281$. Correlation was statistically significant, $\mathrm{p}<0.001$. Regression analysis was then performed to determine causality effect. Model between knowledge score and behaviour score was significant. The predictor variable (knowledge score) accounted for $7.9 \%$ of the variance $[\mathrm{F}(1,387)=33.1$; $\left.\mathrm{p}<0.001 ; \mathrm{R}^{2}=0.079\right]$. Results demonstrate that knowledge does affect behaviour (Figure 2). Thus, for any increase in knowledge score by 1 unit, behaviour score will increase by 0.4 units $(\beta=0.4, \mathrm{t}=5.76$, $\mathrm{p}<0.001)$.

\section{Reliability of the questionnaire}

The testing of the questionnaire yielded the following Cronbach's a values: 0.85 for the knowledge scale and 0.83 for the behaviour scale, which demonstrates good internal consistency and reliability. 


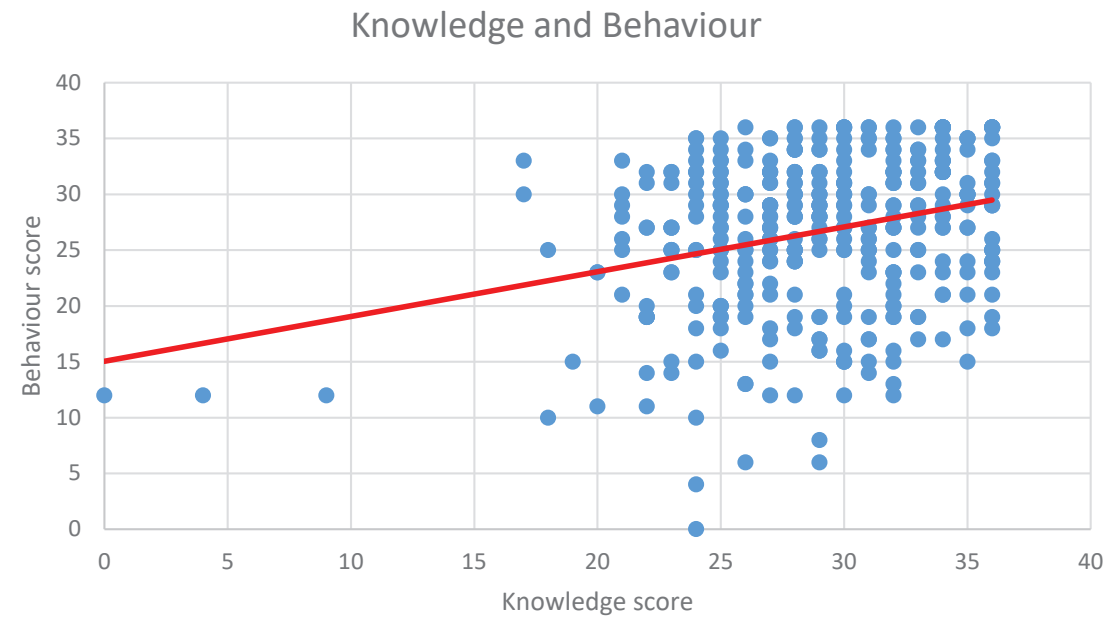

\section{DISCUSSION}

The teachers' mean knowledge score was found to be 28.9 , which is just above the threshold score $(>27)$ for good knowledge. The mean behaviour score was found to be 26.6, which is considered as 'satisfactory behaviour' in terms of avoiding SHS. Pearson correlation testing revealed a significant association between knowledge of SHS and behaviour towards exposure to SHS.

\section{Teachers' knowledge of SHS}

Less than two-thirds of the participants $(63.2 \%)$ were in the 'Good Knowledge' category. The findings from this study corroborate previous studies carried out among highly educated participants, namely, university employees ${ }^{22}$ and university students ${ }^{19}$, whereas low levels of knowledge were noted in studies in low education groups ${ }^{18}$.

This study revealed that almost all the respondents were aware that SHS contains toxic chemicals (98\%) and that it is harmful to the health of passive smokers (99\%). Similar findings were found in a study done by Nuzooa ${ }^{19}$ among university students in Mauritius. Moreover, in the current study among primary school teachers and the previous study among university students, a high percentage of the participants were knowledgeable that there was no safe level of SHS (92.5\% and $81.9 \%$, respectively). On the other hand, respondents in this study were less aware of the specific diseases caused by SHS exposure. This finding was in line with previous studies $^{18,19,21}$ in which participants were less aware of the adverse effects SHS that were not heart and lung related.

\section{Teachers' behaviour towards SHS}

This study showed that teachers appropriately avoided exposure to SHS. Similarly, the relatively high avoidance levels were recorded in the study conducted by Nuzooa ${ }^{19}$ among university students in Mauritius. However, previous studies among highly educated subpopulations like women working at universities ${ }^{21,22}$ showed low levels of avoidance despite the level of knowledge of SHS displayed. Conversely, studies carried out among subpopulations, like general public ${ }^{18}$ and adolescents ${ }^{28,29}$, with lower levels of knowledge of SHS, showed adequate levels of avoidance. It is therefore worth investigating if knowledge acquisition is accompanied by a change of behaviour.

\section{Relationship between knowledge and behaviour}

Data analysis firstly showed a significant association between knowledge and behaviour. Regression analysis secondly revealed that these two variables actually affect each other. Similarly, previous studies suggested a positive relationship between knowledge of SHS and SHS avoidance ${ }^{18,19,30}$. The results of the current study where knowledge explained $7.9 \%$ of variance in behaviour are in line with the findings by Lin et al. ${ }^{30}$ who indicated that knowledge predicted SHS avoidance. On the other hand, a number of 
studies showed that behaviour did not reflect the level of knowledge on SHS of the participants ${ }^{18,19,21,22,28,29,31}$. Evans et al. ${ }^{18}$ argued that if knowledge alone may not explain trends in behaviour, knowledge acquisition is fundamental for any change in behaviour to occur. A significant predictor of protective behaviour towards non-smokers (smoke-free home and smoking abstinence) is knowledge of SHS-related harms ${ }^{18}$. In the same vein, when it comes to SHS avoidance by non-smokers, a powerful predictor of behaviour is self-efficacy ${ }^{30-32}$. High level of self-efficacy was associated with a more avoidant behaviour towards SHS $^{30,31}$. Therefore, it is of fundamental importance to develop knowledge while putting in place the relevant strategies for enhanced self-efficacy.

\section{Strengths and limitations}

This study which targets teachers' knowledge and behaviour towards SHS bridges the gap in the literature with respect to the absence of such studies among this population. The absence of previous research on knowledge and behaviour towards SHS among school teachers is the underlying reason for the inability to compare and contrast our findings with previous studies on similar subjects. Our study uncovers the potential role primary school teachers have in raising awareness among school children on the need for protection from SHS exposure.

Considering the methods used in this study, the knowledge scale and the behaviour scale of the survey instrument, tested in this study, were found to have Cronbach's a values of 0.85 and 0.83 , respectively, thus corresponding to good internal consistency and reliability of the respective scales. Moreover, the study sample was representative of the population of teachers in Mauritius with participants randomly identified from all of the four educational zones of Mauritius.

Being a quantitative study, this survey has as weakness the inability to have an in-depth view of teacher's knowledge and behaviour. A qualitative study is thus recommended to address this limitation and also to explore the perception of teachers with respect to their role in promoting health. The current study underlines the role of teachers, in line with Janz and Becker ${ }^{33}$, as potential actors of awareness on dangers of SHS and protection from SHS exposure.

\section{CONCLUSIONS}

This study showed that the majority of teachers had a good knowledge of the harms of SHS exposure on health and applied this knowledge in their behaviour by keeping away from cigarette smoke. In light of the findings of the study, there is a need for a qualitative study to explore the role of teachers in health education. There is subsequently a need for a multi-stakeholder approach, with primary school teachers as key stakeholder, for the development of school-based prevention programmes. A prior study among school children to assess their knowledge of SHS and to investigate their level of SHS exposure is required for baseline data. A study at national level of all adults of both gender, various age groups, levels of education and work categories is recommended in order to inform decisions at national level on health education programmes on SHS, instead of tobacco smoking, which has so far been the focus of policyholders in Mauritius. These recommendations if implemented by Mauritius and other developing countries will improve the research database, which has the potential to guide policy decisions for better protection of children with respect to exposure to SHS.

\section{REFERENCES}

1. World Health Organization. Tobacco: fact sheet. https:// www.who.int/news-room/fact-sheets/detail/tobacco. Published July 26, 2019. Accessed January 4, 2020.

2. World Health Organization. WHO Framework Convention on Tobacco Control. https://www.who.int/fctc/text_ download/en/. Published 2003. Accessed March 25, 2019.

3. Sandler D, Comstock G, Helsing K, Shore D. Deaths from all causes in non-smokers who lived with smokers. Am J Public Health. 1989;79(2):163-167. doi:10.2105/AJPH.79.2.163

4. World Health Organization. Combating the tobacco epidemic. The world health report 1999: Making a difference. https://www.who.int/whr/1999/en/whr99_ ch5_en.pdf. Published 1999. Accessed December 24, 2019.

5. IARC Working Group on the Evaluation of Carcinogenic Risk to Humans. Tobacco Smoke and Involuntary Smoking. In: IARC Monographs on the Evaluation of Carcinogenic Risks to Humans, No. 83. Lyon, FR: International Agency for Research on Cancer; 2004.

6. National Center for Chronic Disease Prevention and Health Promotion (US) Office on Smoking and Health. The Health Consequences of Smoking-50 Years of 
Progress: A Report of the Surgeon General. Atlanta, GA: Centers for Disease Control and Prevention (US); 2014.

7. Office on Smoking and Health (US). The Health Consequences of Involuntary: Exposure to Tobacco Smoke. Atlanta, GA: Centers for Disease Control and Prevention (US); 2006. https://www.cdc.gov/tobacco/ data_statistics/sgr/2006/index.htm. Accessed January 04, 2020 .

8. Samet JM, Avila-Tang E, Boffetta P, Hannan LM, OlivoMarston S, Thun MJ, Rudin CM. Lung cancer in never smokers: clinical epidemiology and environmental risk factors. Clin Cancer Res. 2009;15(18):5626-5645. doi:10.1158/1078-0432.ccr-09-0376

9. National Center for Chronic Disease Prevention and Health Promotion (US) Office on Smoking and Health. The Health Consequences of Smoking-50 Years of Progress: A Report of the Surgeon General. Atlanta, GA: Centers for Disease Control and Prevention (US); 2014. https://www.ncbi.nlm.nih.gov/pubmed/24455788. Published 2014. Accessed December 26, 2019.

10. Bearer FC. How are children different from adults? Environ Health Perspect. 1995;103(Suppl 6):7-12. doi:10.1289/ehp.95103s67

11. Chao MR, Cooke MS, Kuo CY. Children are particularly vulnerable to environmental tobacco smoke exposure: Evidence from biomarkers of tobacco-specific nitrosamines, and oxidative stress. Environ Int. 2018;120:238-245. doi:10.1016/j.envint.2018.08.006

12. Oberg M, Jaakkola MS, Woodward A, Peruga A, PrüssUstün A. Worldwide burden of disease from exposure to second-hand smoke: a retrospective analysis of data from 192 countries. Lancet. 2011;377(9760):139-146. doi:10.1016/S0140-6736(10)61388-8

13. Anderson HR, Cook DG. Passive smoking and sudden infant death syndrome: review of the epidemiological evidence. Thorax. 1997;52(11):1003-1009. doi:10.1136/thx.52.11.1003

14. Strachan DP, Cook DG. Health effects of passive smoking. 1. Parental smoking and lower respiratory illness in infancy and early childhood. Thorax. 1997;52(10):905914. doi:10.1136/thx.52.10.905

15. Health effects of exposure to environmental tobacco smoke. California Environmental Protection Agency. Tob Control. 1997;6(4):346-353. doi:10.1136/tc.6.4.346

16. Petersen A, Thompson L, Dadi G, Tolcha A, Cataldo J. An exploratory study of knowledge, attitudes, and beliefs related to tobacco use and secondhand smoke among women in Aleta Wondo, Ethiopia. BMC Women Health. 2018;18(1):154. doi:10.1186/s12905-018-0640-y

17. Fenton B, Thankappan K, Champagne B, Lv J, Anthony D. Increased knowledge of the effects of smoking and secondhand smoke encourages smoke-free homes. J Res Nurs. 2014;19(5):373-387. doi:10.1177/1744987114525963

18. Evans KA, Sims M, Judge K, Gilmore A. Assessing the knowledge of the potential harm to others caused by second-hand smoke and its impact on protective behaviours at home. J Public Health (Oxf). 2012;34(2):183-194. doi:10.1093/pubmed/fdr104

19. Nuzooa MA. A quantitative study on the knowledge and behaviour of university students towards secondhand smoke. Mauritius: University of Mauritius; 2015. https://library. uom.ac.mu/libero/WebOpac.cls?VERSION=2\&ACTION= DISPLAY\&RSN=10197552\&DATA=UOM\&TOKEN= qsLZEqxLaV9179\&Z=1\&SET=1. Accessed January 07, 2020.

20. Lee S, Cho A, Lee S, Cho Y, Park E, Kim Y, Lee J. Secondhand smoke knowledge, sources of information, and associated factors among hospital staff. PLoS ONE. 2019;14(1):e0210981. doi:10.1371/journal.pone.0210981

21. Gharaibeh H, Haddad L, Alzyoud S, El-Shahawy O, Baker NA, Umlauf M. Knowledge, attitudes, and behavior in avoiding secondhand smoke exposure among non-smoking employed women with higher education in Jordan. Int J Environ Res Public Health. 2011;8(11):4207-4219. doi:0.3390/ijerph8114207

22. Zabadi H, Tarayra A, Ghnima R, Jarar A, Khdor H, Kdarat T. Exposure evaluation of environmental tobacco smoke: Gender and socioeconomic disparities in a low income Country-Palestine. Health Scie J. 2016;10(6):1. doi:10.21767/1791-809X.1000472

23. Tot V, Zvezdin B. Assessment of knowledge, behavior and attitude of school children towards smoking. J Pulm Respir Med. 2015;5(297):2. doi:10.4172/2161-105X.1000297

24. Sahib AJ, Al-Badri HJA. Assessment of the knowledge and attitudes of preliminary school students toward smoking in Baghdad. Epidemiol Biostat Public Health. 2016;13(1). doi:10.2427/11612

25. Chan Sun M. Survey instrument to assess knowledge of the causal relationship of second-hand smoke with diseases, based on US Surgeon General Report of 2014. Oral presentation at: 2015 World No Tobacco Day, Mauritius.

26. El Sherbiny, El Essawy, Abdel K. Knowledge and attitude towards smoking among Fayoum university students. J High Inst Publ Health. 2010;40(3):573-585. doi:10.21608/JHIPH.2010.20621

27. Norman G. Likert scales, levels of measurement and the 'laws' of statistics. Adv Health Sci Educ Theory Pract. 2010;15(5):625-632. doi:10.1007/s10459-010-9222-y

28. Schwartz J, Graham RB, Richardson CG, Okoli C, Struik LL, Bottorff JL. An examination of exposure and avoidance behavior related to second-hand cigarette smoke among adolescent girls in Canada. BMC Public Health. 2014;14(1):468. doi:10.1186/1471-2458-14-468

29. Richardson C, Schwartz J, Struik L, Bottorff J. Adapting the Stage of Change model to investigate adolescent behavior related to reducing second hand smoke exposure. Open J Prev Med. 2013;3(2):160-164. doi:10.4236/ojpm.2013.32021

30. Lin PL, Huang HL, Lu KY, Ghen T, Lin WT, Lee 
CH, Hsu HM. Second-hand smoke exposure and the factors associated with avoidance behavior among the mothers of pre-school children: a school-based crosssectional study. BMC Public Health. 2010;10(1):606. doi:10.1186/1471-2458-10-606

31. Ja-yin L, Hyunmi A, Hyeonkyeong L. Factors Affecting Secondhand Smoke Avoidance Behavior of Vietnamese Adolescents.Int J Environ Res Public Health. 2018;15(8):1632. doi:10.3390/ijerph15081632

32. Borland R. Theories of behavior change in relation to environmental tobacco smoke control to protect children. In: International Consultation on Environmental Tobacco Smoke (ETS) and Child Health background paper series. Geneva, Switzerland: World Health Organization.

33. Janz N, Becker M. The health belief model: A decade later. Health Educ Q. 1984;11(1):1-47. doi:10.1177/109019818401100101
ACKNOWLEDGEMENTS

The authors thank the teachers for their participation as well as the Ministry of Education and Human Resources, Tertiary Education and Scientific Research and Service Diocésain de l'Education Catholique for their authorization to access the public and private schools, respectively.

CONFLICTS OF INTEREST

The authors have completed and submitted the ICMJE Form for Disclosure of Potential Conflicts of Interest and none was reported.

FUNDING

There was no source of funding for this research.

PROVENANCE AND PEER REVIEW

Not commissioned; externally peer reviewed. 